\title{
Human Thermo-Physiological Sensation Control Based in the Adaptive Comfort Philosophy
}

\author{
Eusébio Z. E. Conceição*. João P. Farinho*. Ma Manuela J. R. Lúcio** \\ *Faculty of Sciences and Technology, University of Algarve, Gambelas Campus, 8005-139 Faro, Portugal (Tel: 00351 \\ 289800900; e-mail: econcei@ualg.pt). \\ **Vertical Grouping of Schools Professor Paula Nogueira, Rua da Comunidade Lusíada, 8700-248 Olhão, Portugal (e-mail: \\ maria.manuela.lucio@gmail.com)
}

\begin{abstract}
In order to improve the building thermal efficiency, increase the human thermal comfort level and to reduce the building energy consumption, in this work, the human thermo-physiological sensation control, based in the adaptive comfort philosophy, is applied. In this control methodology the occupants, during a lesson activity, can choose among the clothing level, the activity level and the natural ventilation system. The PMV and PPD indexes are used in the numerical simulation. This work is made in a classroom school building, in the Algarve region, with Mediterranean characteristics, in Spring conditions, based in air temperature and relative humidity measurements. The comparison of the human thermal comfort level without and with control strategies is made. The obtained results are used to define an applicable activity, clothing and ventilation strategy, during the day.
\end{abstract}

Keywords: Control strategies, PMV index, Thermal-physiology, Adaptive thermal comfort.

\section{INTRODUCTION}

An efficient building promotes a high human thermal comfort level with low building energy consumption. In order to obtain acceptable comfort conditions a heating, air conditioning and ventilating system can be used. The first two systems are associated to the energy consumption, however the third one, when the natural ventilation is considered, are associated to low energy consumption levels. The idea of this work is to use the adaptive thermal comfort strategies, using the natural ventilation and other personal factors, in order to improve the thermal comfort level that the occupants are subjected, with energy save.

In general the classrooms, in the Algarve region, are not equipped with heating, forced ventilating and airconditioning systems. The main ventilation system works by natural means using a crossed or hybrid ventilation philosophy. In general, the ventilation is guaranteed by small windows, placed above the door and windows level, or by windows and door. In warm and moderate environmental conditions, when the air temperature increases, due to the inlet solar radiation, the fabrics curtains are used (also see Conceição et al., 2008).

In order to evaluate the thermal comfort level, in moderate environments equipped with heating or air-conditioning systems, either in cold or in warm climates during Winter or Summer conditions, the PMV (Predicted Mean Vote) and the
PPD (Predicted Percentage of Dissatisfied) indexes, developed in Fanger (1970) and presented in ISO 7730 (2005) are used. The PMV index is given as a value on the seven-point comfort scale ( -3 cold; -2 cool; -1 slightly cool; 0 neutral; 1 slightly warm; 2 warm and 3 hot) and is based in four environmental parameters (air mean temperature, velocity and relative humidity and radiant mean temperature) and two personal factors (clothing and metabolic activity levels). In accord to the main stream of the PMV and PPD indexes, the thermal neutrality of an individual is obtained when the body heat loss is equal to the body metabolic heat $(\mathrm{PMV}=0)$. For acceptable thermal comfort conditions, the ISO 7730 (2005) defines three comfort categories (A, B and $\mathrm{C})$, establishing limits for PMV and PPD indexes. The PMV index values in category A change between -0.2 and 0.2 (percentage of dissatisfied people less than $6 \%$ ), in category B between -0.5 and 0.5 (percentage of dissatisfied people less than $10 \%$ ) and in category $\mathrm{C}$ between -0.7 and 0.7 (percentage of dissatisfied people less than $15 \%$ ).

The thermal comfort "static" model, presented in Fanger (1970) and ISO 7730 (2005), is based only on the body's thermal balance (mass and heat exchanges) with the surrounding environment and the internal body temperature is maintained through some physiological responses. Nevertheless, other factors like physical, physiological or others, can interact with the thermal sensation and comfort (see de Dear et al. (1997)). Thus a new "adaptive" model, based on the behavioural adjustment, physiological and psychological, was developed by de Dear et al. (1997). In the 
first category (behavioural adjustment), the ability to change the human body heat and mass thermal balance is considered, being also considered the personal adjustments (like clothing, activity, posture, locations and others), technological or environmental adjustments (like the control of the surrounding with heating, ventilating or refrigerating systems and others) and cultural adjustments. In the second one (physiological), the changes in the adaptation physiological responses due to the thermal environment exposure with the gradual diminution of the initial strain are considered, namely, the genetic adaptation (like the changes of the genetic heritages) and acclimation (like some changes in the thermoregulatory system during a time period). Finally, in the third one (psychological) the psychological adaptation to the indoor environment due the altered perception and attenuated expectation is considered. In general, this adaptive model is frequently a regression equation between a climate surrounding neutral temperature preferred by the people and the outdoor temperature.

The objective of this work is to evaluate the thermal comfort conditions, that school students are subjected, without and with control of the environmental and personal variables during one day. Without control the students are not subjected, during the school activities, to the variation in the environmental and personnel variables, while with control the occupants can select the clothing level, the activity level and the internal air velocity (in function to the adopted strategy).

\section{WITHOUT CONTROL STRATEGIES}

In the evaluation of the thermal comfort level, using the PMV index, without variations of the environmental and personal variables, during the day, the clothing level is $0.75 \mathrm{Clo}$, the activity level is 1.2 Met and the mean air velocity is $0.17 \mathrm{~m} / \mathrm{s}$ (Conceição et al., 2008).

\section{WITH CONTROL STRATEGIES}

In the evaluation of the thermal comfort level, using the PMV index, with variations of the environmental and personal variables, during the day, the occupants can select among the clothing level, activity level and the natural ventilating system. In the numerical simulation, using the PMV and PPD indexes, the Fanger model (Fanger, 1970) is used.

The activity level, obtained through the ISO 7730 (2005), in these experimental tests, was controlled by the sort of activity made in each lesson and can change between 1.2 and 1.3 Met. This strategy is guaranteed, during the lesson activity, by the introduction of different activities levels. The teachers, in function to the thermal suggestion of the students, can change the lesson activity.

The clothing level, obtained using the sum of the different clothed considered, can be changing between 1.3 Clo. (Shoes, socks, underwear shirt with long sleeves, shirt with long sleeves, trousers, sweater and jacket), 0.95 Clo. (Socks, shoes, underwear shirt with long sleeves, shirt with long sleeves, trousers and sweater), 0.75 Clo. (Underwear, shirt, trousers, socks and shoes), 0.68 Clo. (Panties, socks, shoes, trousers, t-shirt, sweater), 0.52 Clo. (Panties, light-weight long sleeves shirt, trousers, socks and shoes) and 0.39 Clo. (Short sleeves shirt, shorts, shoes and socks). This strategy is guaranteed in the previous day (with the definition of main and adequate clothing level) and during the lesson activity (with lightly changes in some external clothing).

In this study the occupants can select among opening the small window, located above the windows and door, opening the windows and door or close all windows and doors. The three main topologies are $0.00 \mathrm{~m} / \mathrm{s}$ (All door, windows and small windows are closed, being the internal air recirculation verified during break times when the door is open), $0.17 \mathrm{~m} / \mathrm{s}$ (The door and window are closed and the small windows, located above the door and windows level, are open) and 0.58 $\mathrm{m} / \mathrm{s}$ (The door and windows are open). The mean air velocity, calculated inside the room for the considered different air topology, are presented in Conceição et al. (2008).

In figure 1 the scheme of the control strategies, evaluated by the occupants preference, used in this work is shown.

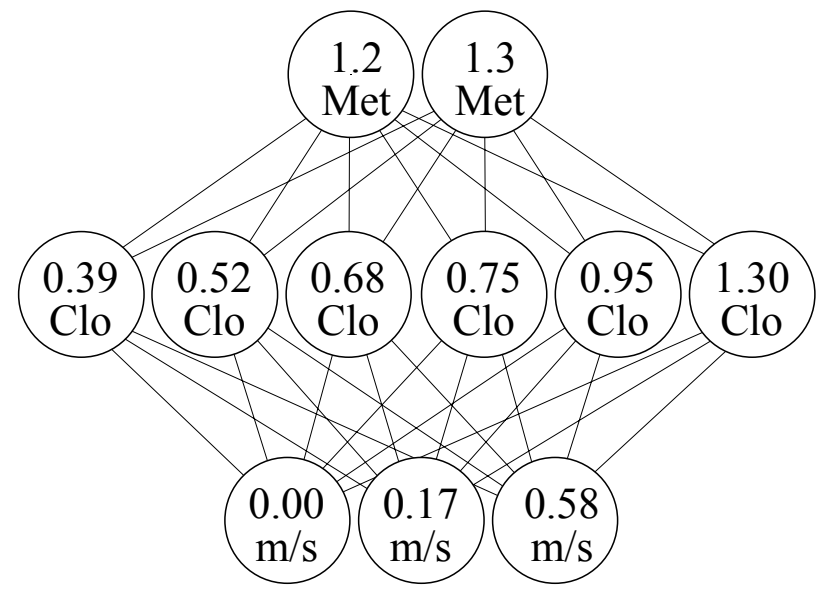

Fig. 1. Control strategies used in this work.

The obtained results, when the control strategy is applied, during one day, are associated to the combination of different clothing levels, activity levels and the natural ventilating systems that promote the best thermal comfort level. Numerically, this calculus is made using the different combination and identify the combination that guarantees the lower PPD values.

\section{RESULTS AND DISCUSSION}

In this study, made in a moderate thermal environmental conditions day of April, the air temperature (see figure 2) and 
relative humidity (see figure 3) are experimentally obtained. The mean radiant temperature is considered equal to the air temperature value.

This study is divided in two phases: in the first one, without control strategy, a real situation similar to the one that occupants are subjected is evaluated, while in the second one, with control strategy, an optimal situation is predicted, where the occupants, in accord to their thermal preferences, can change among the activity level, clothing level and air velocity level.

In figures 4 and 5 the evolution of PMV and PPD indexes, without control strategy is presented.

When the control strategy is considered, the evolution of the activity level, clothing level and air velocity are presented, respectively, in figures 6,7 and 8 , while, the evolution of PMV and PPD indexes are presented, respectively, in figures 9 and 10.

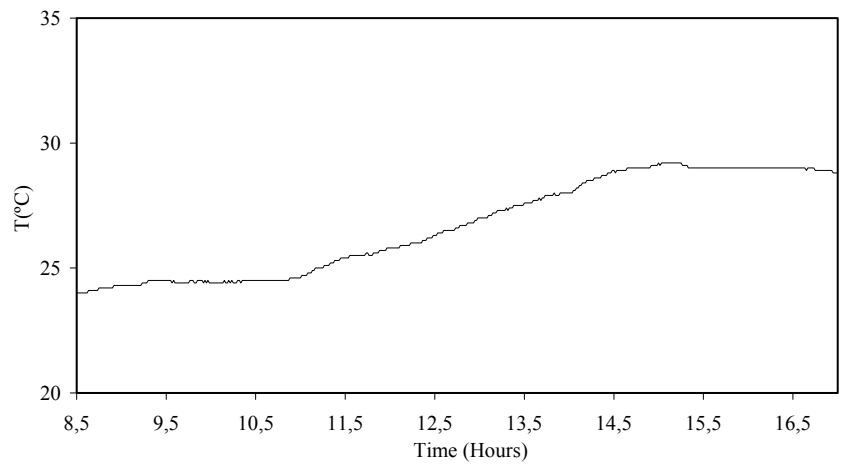

Fig. 2. Evolution of air temperature, T, measured inside the analysed classroom.

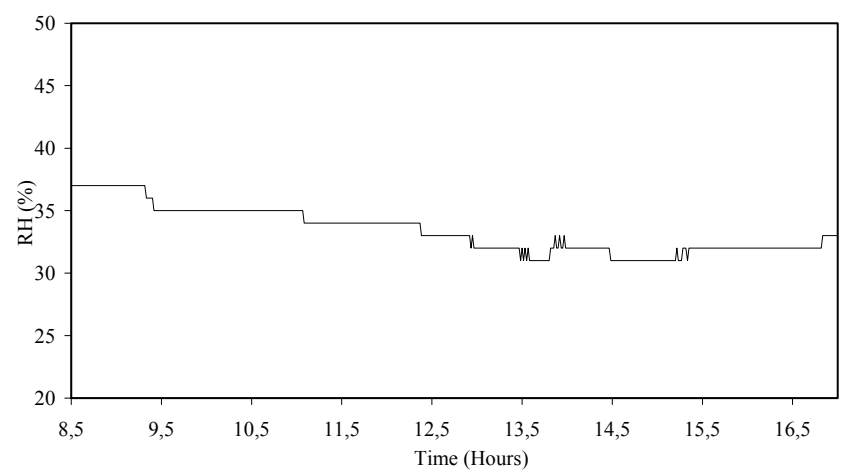

Fig. 3. Evolution of air relative humidity, RH, measured inside the analysed classroom.

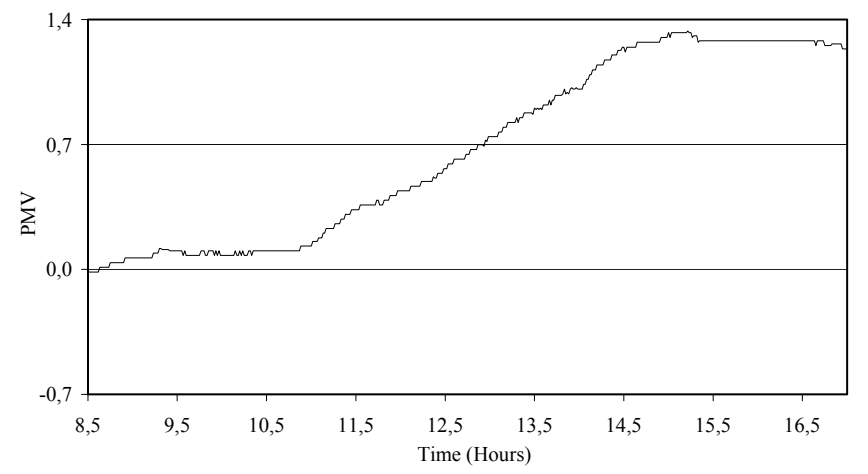

Fig. 4. Evolution of PMV index calculated inside the analysed classroom, without control strategy.

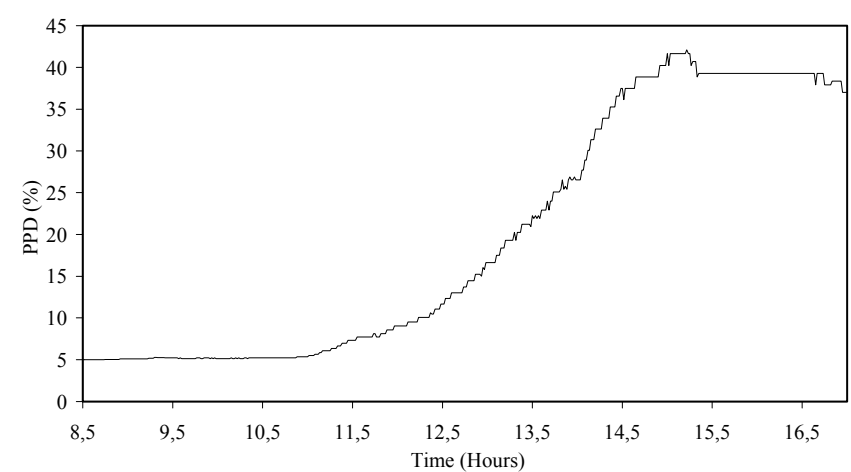

Fig. 5. Evolution of PPD index calculated inside the analysed classroom, without control strategy.

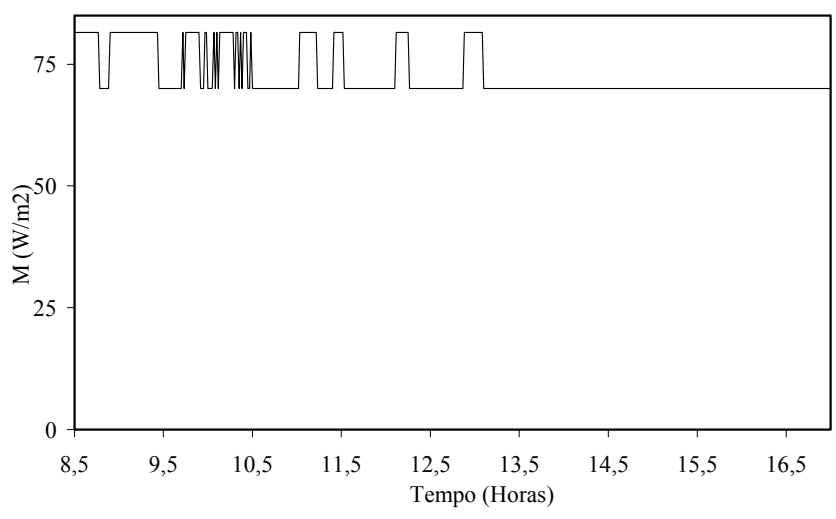

Fig. 6. Evolution of activity level, M, evaluated inside the analysed classroom, with control strategy. 


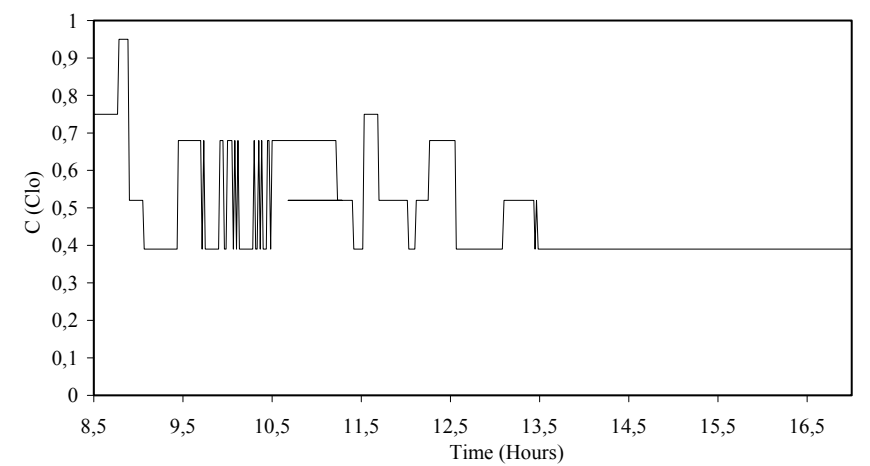

Fig. 7. Evolution of clothing level, C, evaluated inside the analysed classroom, with control strategy.

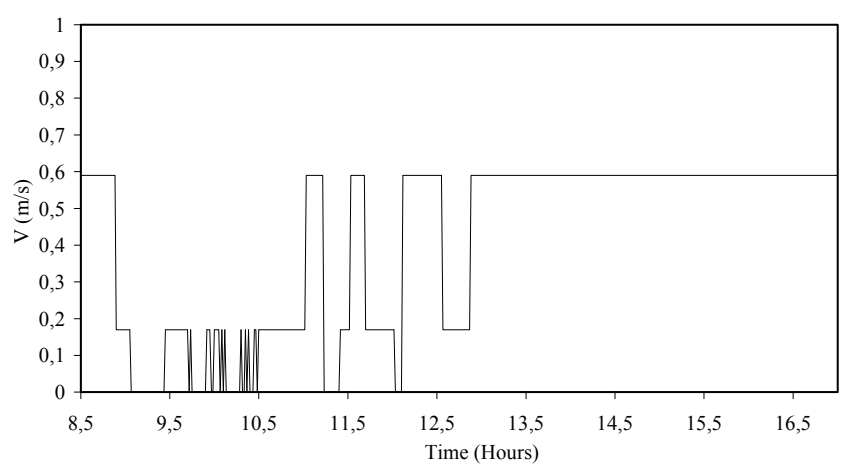

Fig. 8. Evolution of air velocity evaluated inside the analysed classroom, with control strategy.

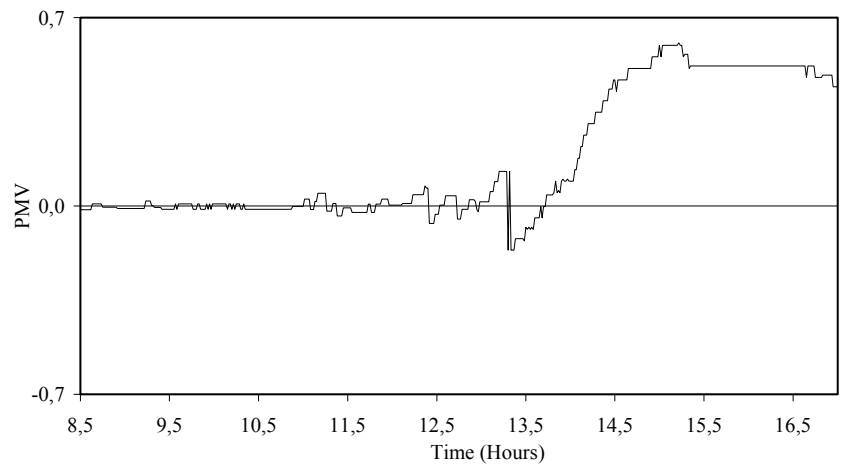

Fig. 9. Evolution of PMV index evaluated inside the analysed classroom, with control strategy.

In accord to the measured values is possible to verify that the air temperature, that increases during the day, changes in general between the 24 and $30{ }^{\circ} \mathrm{C}$, while the air relative humidity, that decreases during the day, change between the 31 and $37 \%$.

In a real situation, without control strategies (without occupants' thermal preferences), the classroom is thermally comfortable, in accord to the ISO 7730 (2005), during the morning. In the afternoon the PMV and the PPD indexes increase for uncomfortable values.

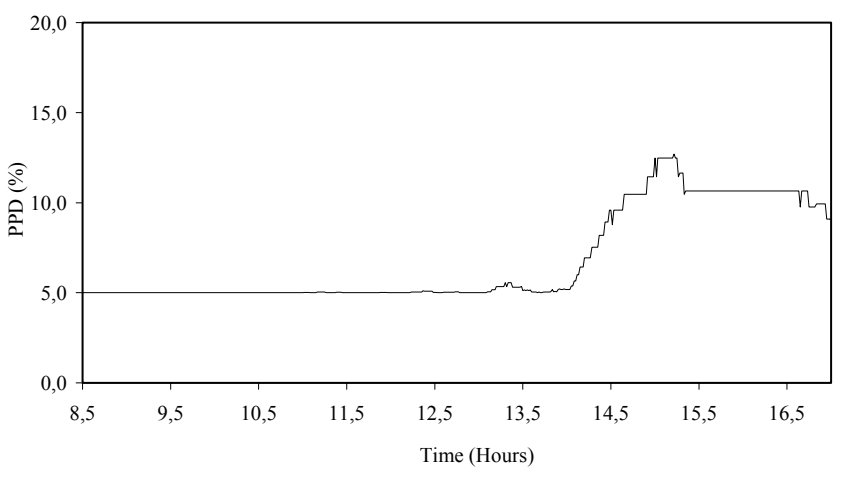

Fig. 10. Evolution of PPD index evaluated inside the analysed classroom, with control strategy.

When the occupants thermal preferences (control strategies) of the activity, clothing and natural ventilation situation, by the occupants are considered, the thermal comfort level during the morning is in accord to the optimal thermal conditions (PMV=0), while in the afternoon the PMV and the PPD increases, nevertheless, the thermal comfort conditions are acceptable in accord the Category C of ISO 7730 (2005).

In the last situation, with control strategies, the occupant in a Spring day, in general, prefers:

- high activity levels in the beginning of the morning and low activity levels at the end of the morning and afternoon,

- high clothing level in the beginning of the morning, moderate clothing level at the end of the morning and low clothing level during the afternoon

moderate air velocity level in the morning and high air velocity level in the afternoon.

\section{CONCLUSIONS}

In this work the human thermo-physiological sensation control, based in the adaptive comfort philosophy, is applied. The study is made in a classroom building, in the Algarve region, with Mediterranean characteristics, in Spring condition.

The thermal comfort level, without the occupants preferences, is acceptable during the morning, in accord to Category C of the ISO 7730 (2005), and non acceptable during the afternoon. When the occupants' preferences are applicable, the thermal comfort level is acceptable during the morning, with optimal conditions, and acceptable in the afternoon, in accord to Category C of the ISO 7730 (2005). 
When the control strategies are considered, the occupant, in general, prefers activity levels of 1.3 Met. in the beginning of the morning and 1.2 Met. at the end of the morning and afternoon, prefers clothing levels of $0.75 \mathrm{Clo}$. in the beginning of the morning, 0.52 Clo. at the end of the morning and 0.39 Clo. during the afternoon and prefers air velocity of $0.17 \mathrm{~m} / \mathrm{s}$ in the morning and $0.58 \mathrm{~m} / \mathrm{s}$ in the afternoon.

In the application of the methodology developed in this work, two philosophies can be implemented. In the first one, the results can be used directly as suggestions to the occupants to the used personal parameters (activity and clothing levels) and the windows and door state, while in the second one, the results can be used directly as suggestions to the occupants to the used personal parameters and directly to HVAC control systems.

In both suggestions presented previously the environmental variables, used in the numerical program run in a personal computer, can be measured directly or use an environmental variables database. In the first situation a control iterative methodology can be used, while in the second one, important information can be obtained previously in order to improve the student performance in the classroom.

\section{ACKNOWLEDGMENTS}

This research activity is being developed inside a project financed by the City Council of Olhão.

This research activity is being developed inside a project approved and sponsored by the Portuguese Foundation for Science and Technology, POCI 2010, sponsored also by the European Comunitary Fund FEDER.

\section{REFERENCES}

Conceição, E.Z.E., Lúcio, MaM.J.R., Vicente V.D.S.R. and Rosão, V.C.T. 2008. Evaluation of local thermal discomfort in a classroom equipped with crossed ventilation. The International Journal of Ventilation, UK, Vol. 7, N. 3, December 2008, pp. 267-277.

de Dear, R., Brager, G. and Cooper, D., 1997. Developing an Adaptive Model of Thermal Comfort and Preference. ASHRAE RP-884.

Fanger, P. O. 1970. Thermal comfort: analysis and applications in environmental engineering, McGraw-Hill Book Company, United States.

ISO 7730, 2005. Ergonomics of the thermal environments analytical determination and interpretation of thermal comfort using calculation of the PMV and PPD indices and local thermal comfort criteria. International Standard. Switzerland. 